\title{
Applicability of AI/P (Aluminium/Phosphorus) Ratio in SeDAF Process for Enhanced Phosphorus Removal
}

\author{
Yeoju Jang ${ }^{1 \odot} \cdot$ Jinhong Jung ${ }^{2 \odot} \cdot$ Kwangho Ahn $^{2 \odot} \cdot$ Hyunman Lim $^{2 \odot} \cdot$ Weonjae Kim $^{2+\oplus}$ \\ 'University of Science and Technology (UST, KICT School), Civil \& Environmental Engineering \\ ${ }^{2}$ Korea Institute of Civil Engineering and Building Technology (KICT), Department of Land, Water and Environment Research, \\ Environmental Resource Research Center
}

(Received August 18, 2020; Revised October 22, 2020; Accepted November 9, 2020)

\begin{abstract}
Objectives: To prevent eutrophication and algal blooms, Ministry of Environment in Korea has reinforced the effluent standards of wastewater treatment facilities. In the last 20 years, various advanced wastewater treatment processes have been introduced nationwide. The sedimentation-dissolved air flotation (SeDAF) process has been developed for efficient enhanced phosphorus removal in the previous researches. In the study, several factors were reviewed to examine the operation characteristics of the SeDAF process. In particular, the applicability of aluminium/phosphorus $(\mathrm{Al} / \mathrm{P})$ and aluminium/turbidity $(\mathrm{Al} / \mathrm{T})$ ratios were investigated intensively.
\end{abstract}

Methods: To derive the appropriate operating conditions for the SeDAF process, several sets of lab-scale tests were carried out. For each operating condition, $\mathrm{Al} / \mathrm{P}$ (Al/T-P), $\mathrm{Al} / \mathrm{PO}_{4}{ }^{3-}-\mathrm{P}$, and $\mathrm{Al} / \mathrm{T}$ ( $\mathrm{Al} /$ Turbidity) ratios were analyzed, compared and reviewed respectively.

Results and Discussion: Al/P ratio was revealed as the most prominent factor in terms of stability and feasibility of operation, and $\mathrm{Al} / \mathrm{P}$ values of the SeDAF process could achieve lower values than those of other processes in the previous researches.

Conclusions: It could be expected that the coagulant dosage decision using $\mathrm{Al} / \mathrm{P}$ ratio has many advantages to reduce coagulant dosage and to decrease the amount of sludge production in the SeDAF process.

Keywords: Sedimentation·Dissolved Air Flotation (SeDAF), Enhanced Phosphorus Removal, Al/P Ratio, Al/T Ratio, Advanced Wastewater Treatment

The Korean text of this paper can be translated into multiple languages on the website of http://jksee.or.kr through Google Translator. 


\title{
연구논문
}

\section{인 고도처리를 위한 침전부상공정(SeDAF)에서 $\mathrm{Al} / \mathrm{P}$ 비(aluminium/phosphorus ratio)의 적용성 검토}

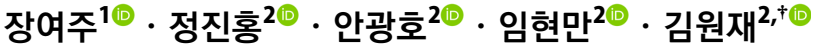 \\ ${ }^{1}$ 과학기술연합대학원대학교 건설환경공학 \\ 2한국건설기술연구원 국토보전연구본부 환경자원재생연구센터
}

\begin{abstract}
목적: 부영양화 및 조류 발생을 방지하기 위하여 환경부에서는 하수처리시설의 방류수 수질기준을 강화해 왔으며, 지난 20년간 전국적으로 다양한 인 고도처리시설이 도입되었다. 기존의 인 고도처리공정을 효율적으로 대체할 수 있는 일체형 침전부상공정(sedimentation-dissolved air flotation process; SeDAF process)이 이전 연구에서 개발된 바 있다. 본 연구에서는 $\mathrm{SeDAF}$ 공정의 운영조건을 도출하기 위해 다양한 운전인자를 검토하였고, 특히, 알루미늄/ 인(Al/P)비 및 알루미늄/탁도(Al/T)비의 적용성을 평가하였다.
\end{abstract}

방법 : SeDAF 공정의 적정 운전조건을 도출하기 위하여 여러 Lab-scale 모의실험을 수행하였다. 각 운전조건에 대 해 $\mathrm{Al} / \mathrm{P}(\mathrm{Al} / \mathrm{T}-\mathrm{P})$ 비, $\mathrm{Al} / \mathrm{PO}_{4}{ }^{3-}-\mathrm{P}$ 비 및 $\mathrm{Al} / \mathrm{T}$ ( $\mathrm{Al} /$ Turbidity)비를 분석하고 비교·검토하였다.

결과 및 토의 : $\mathrm{Al} / \mathrm{P}$ 비가 안정성 및 운전용이성 측면에서 가장 우수하였으며, $\mathrm{SeDAF}$ 공정에서는 기존 문헌에서 보 고된 $\mathrm{Al} / \mathrm{P}$ 비의 범위보다 낮은 조건에서도 양호한 처리효율을 달성할 수 있는 것으로 나타났다.

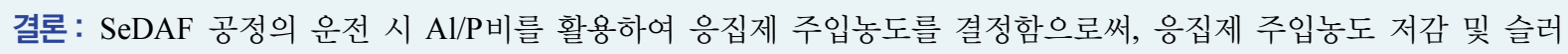
지 발생량 감소 등 여러 이점을 얻을 수 있을 것으로 기대한다.

주제어: 침전부상공정(SeDAF), 인 고도처리, 알루미늄/인 비, 알루미늄/탁도 비, 하수고도처리

\section{1. 서론}

호수 및 하천의 부영양화로 인한 조류 대발생은 남조류 독소 및 맛·냄새 유발물질 증가의 원인이 되며, 정수처리공 정에서 여러 문제를 발생시킬 수 있다. ${ }^{12)}$ 조류발생 원인 중 하나인 부영양화는 하수처리장 방류수 및 축산농가 등으로 부터 유출되는 오염물질 등에 의한 것으로 보고된 바 있 다. ${ }^{3,4)}$ 이를 방지하기 위하여 환경부는 1996년 이후 하수처 리시설의 방류수 수질기준에 총인(T-P) 항목을 추가하였고, 2012년 이후에는 방류수 수질기준을 $0.2-2.0 \mathrm{mg} / \mathrm{L}$ 로 강화 하는 등 공공수역 수질관리의 문제점으로 파악되는 총인처 리에 대한 요구가 강조되고 있다.,5) 이에 따라 국내 공공하 수처리시설에서는 인 제거효율이 높은 인 고도처리 방식을 도입하였으며, 하수처리시설 625 개소 중 330 개소에서 인 고도처리시설을 도입하여 운영하고 있다. ${ }^{7-9)}$

인 고도처리시설에서는 일반적으로 응집공정 이후 침전, 부상 및 여과공정 등이 적용되며, 이 과정에서 응집제 주입 이 필요하게 된다. 응집제를 주입하여 오염물질을 제거하는
공정에서 원수 내 여러 제거대상 오염물질의 농도와 주입된 응집제 농도의 비에 대한 고찰이 이루어져온 바 있다. 알루 미늄계열의 응집제를 사용할 경우에는 (1) 주입된 알루미늄 농도( $\mathrm{Al}) /$ 원수의 인(P) 농도 또는 (2) 주입된 알루미늄 농도 $(\mathrm{Al}) /$ 탁도(turbidity)가 주요한 고려대상이 될 수 있다. $\mathrm{Al} / \mathrm{P}$ 비의 경우 하수처리공정의 3 차 처리에서 주로 활용되는 개 념이며, $\mathrm{Al} /$ Turbidity $(\mathrm{Al} / \mathrm{T})$ 의 경우 정수처리공정에서 ALT 비라고도 일컬어지는 개념으로, 두 값 모두 수치가 작을수 록 동일한 농도의 처리대상물질에 대해 더 적은 농도의 응 집제를 주입한다는 의미이기 때문에 경제성 측면에서 우수 하다고 할 수 있다. ${ }^{10}$ 기존 연구에서 하수처리공정에서의 $\mathrm{Al} / \mathrm{P}$ 비에 대한 사례 분석이 이루어졌으며, $\mathrm{Al} / \mathrm{P}$ 비는 원수의 농도 범위, 처리수질(제거효율) 및 $\mathrm{pH}$ 등 다양한 인자에 의 해 영향을 받으며, 원수농도가 감소할수록 또는 달성하고자 하는 처리수질이 낮을수록 $\mathrm{Al} / \mathrm{P}$ 비의 값이 증가하는 것으로 보고되고 있다. 유입수 T-P $5-13.8 \mathrm{mg} / \mathrm{L}$ 에서 처리수 T-P $0.5-1 \mathrm{mg} / \mathrm{L}$ 달성을 위한 $\mathrm{Al} / \mathrm{P}$ 비는 1.9 - 3.7의 범위로 분석 된 바 있으며 ${ }^{11,12)}$, 국내 플랜트 운영을 통한 분석에 따르면, 


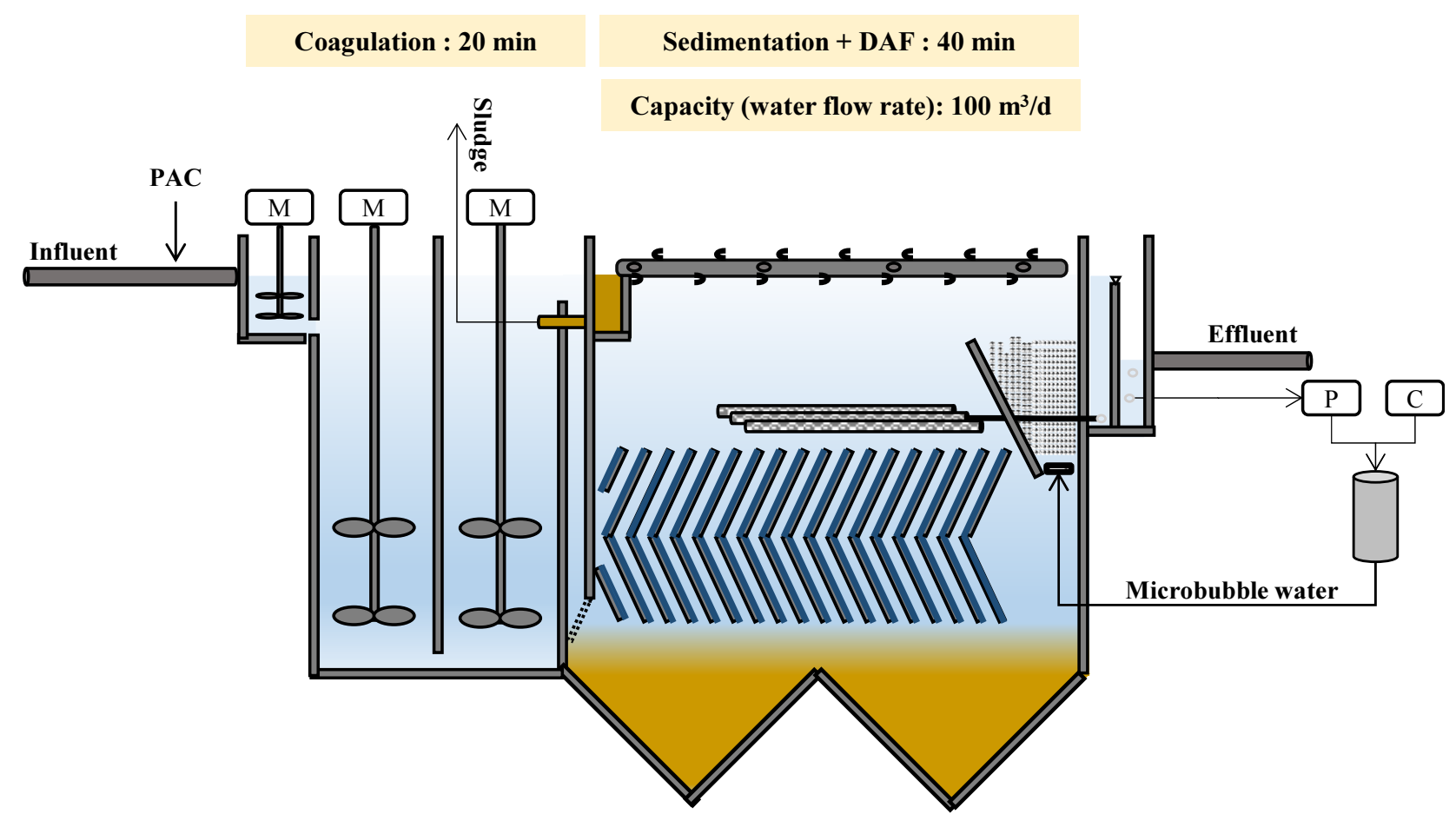

Fig. 1. Conceptual diagram of SeDAF plant.

유입수 T-P $0.5-2.0 \mathrm{mg} / \mathrm{L}$ 의 범위에서 처리수 T-P $0.2 \mathrm{mg} / \mathrm{L}$ 이하를 달성하기 위한 $\mathrm{Al} / \mathrm{P}$ 비는 1.0 - 7.2의 범위로 분석된 바 있다(공법에 따른 차이 고려하지 않음). ${ }^{7}$

본 연구에서는 기존의 인 고도처리공정의 단점을 보완하여, 응집제 소모 및 그에 따른 슬러지 발생 측면에서의 경제성 을 향상시킨 신공정인 '일체형 침전부상공정(sedimentation. dissolved air flotation process; SeDAF process) ${ }^{13)}$, 의 운전특 성 검증을 위한 Lab-scale 단위 실험을 수행하였으며, 주입 응집제농도에 따른 알루미늄과 인 등 수질인자의 비(ratio) 를 도출 및 분석하였다.

\section{2. 재료 및 방법}

\section{1. 일체형 침전부상공정(SeDAF)의 개요}

일체형 침전부상공정(SeDAF)의 개요는 Fig. 1과 같으며, 공정의 개념에 대하여서는 기존의 문헌에서 제시된 바 있 다. ${ }^{13)}$ 반응조는 혼화, 응집, 침전부상조로 구성되어 있다. 침 전부상조는 하부와 상부가 각각 침전부 및 부상부로 구성되 어 있으며, 두 공정은 한 반응조 내에서 격벽 없이 구성되어 있으나 수류의 흐름은 침전공정 완료 후 부상분리공정의 순 서로 형성된다. 응집이 완료된 원수는 하부의 침전부로 유 입되어 수평한 흐름으로 이동하는 과정에서 밀도가 높은 침 강성 플록이 침전하여 제거된다. 조의 말단부에 다다라서 미세기포수(가압수)가 유입되어 수직으로 상승하는 흐름을 형성한다. 부상분리공정에서의 수류는 침전부 상부에서 반 대 방향으로 수평하게 흐르게 되며 이 과정에서 미세기포에
의하여 저밀도의 부상성 플록이 분리된다. 이후 처리수는 조의 중간부에 있는 최종처리수 유공관으로 유입되어 별도 의 동력 사용 없이 최종처리수조로 이동한다. 원수는 유입 후 [혼화조-응집조-침전부상조-최종처리수조]의 순서로 이동한다.

\subsection{Jar-test 기반 침전부상공정 모의실험 개요}

본 연구에서는 하수처리장 방류수의 인 제거를 위하여 기 존 인 고도처리공정의 대안으로 적용할 수 있는 $\mathrm{SeDAF}$ 공 정의 운전인자를 검토하기 위하여 응집-침전-부상공정을 모 의하는 Jar-test를 수행하였다.

인 고도처리를 위한 $\mathrm{SeDAF}$ 공정의 실험실 규모 분석은

Fig. 2와 같이 Jar-test를 기반으로 진행되었다. $2 \mathrm{~L} \mathrm{Jar}$ 에 원 수를 충전하여 급속교반 0.5 분, 1 차 완속교반 10 분, 2 차 완 속교반 10 분으로 구성하였으며, 교반강도는 순서대로 200 $\mathrm{rpm}\left(400 \mathrm{sec}^{-1}\right), 85 \mathrm{rpm}\left(115 \mathrm{sec}^{-1}\right)$ 및 $45 \mathrm{rpm}\left(40 \mathrm{sec}^{-1}\right)$ 으 로 실시하였다. 교반완료 시점으로부터 20 분간 정치하여 침 전공정 모의실험을 수행하였다. 침전공정 완료 후 분석시료 와 부상공정 모의실험을 위한 실험수를 상등액에서 동시 채 수하였다. 부상공정을 위해 침전공정 완료실험수 $1 \mathrm{~L}$ 에 미 세기포수 $150 \mathrm{~mL}$ (Jar-test수의 $15 \%$ )를 하부에 주입하였으 며, 미세기포수 주입 5 분 후 분석시료를 하단부에서 채수하 였다(Platypus ${ }^{\circledR}$ DAF Jar-tester 실험장치 이용). 미세기포수 는 압력탱크에 물과 공기를 주입한 후 탱크 내부를 4-5 $\mathrm{kg}_{\mathrm{f}} / \mathrm{cm}^{2}$ 로 유지하며 과포화수를 생성한 뒤 대기압 상태로 분출시켜 제조하였다. 미세기포수 조제를 위해 증류수를 사 


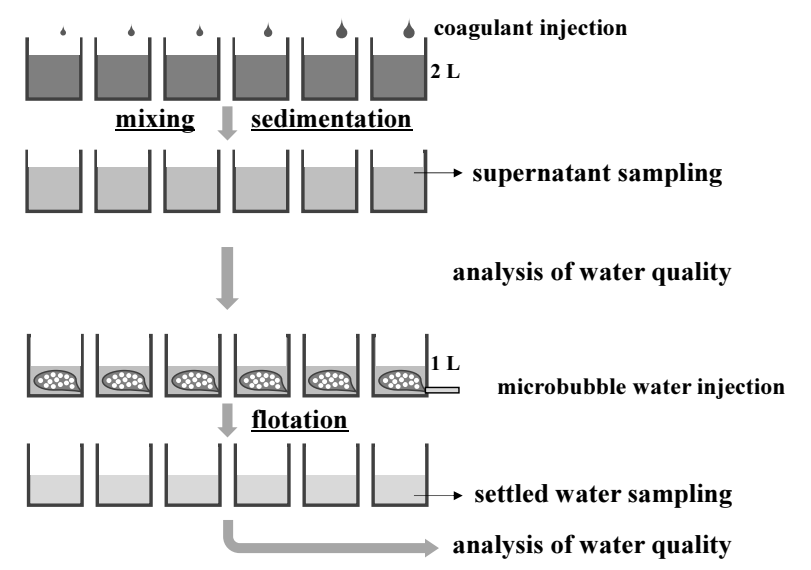

Fig. 2. Procedure of sedimentation and flotation jar-test.

용하였으며, 부상공정 설정 시간은 발생한 $30 \mu \mathrm{m}$ 이상의 미세기포가 전부 부상하는 시간에 $50 \%$ 의 안전율을 추가로 고려하여 설정하였다. 해당 침전 및 부상공정은 단일공정에 대한 모의실험에 해당하며, 두 공정을 아우르는 전체공정은 침전부상공정의 모의실험에 해당하는 것으로 간주하였다.

원수는 경기도 고양시 소재 일산친환경사업소의 고도처 리 유입수인 2차침전지 유출수를 대상으로 하였으며, 실험 의 제어조건은 원수 총인(T-P) 농도를 기준으로 설정하였다. 원수 범위는 비고도처리시설 방류수 및 인 고도처리공정 유 입수의 일반적 T-P 농도인 $0.03-3.0 \mathrm{mg} / \mathrm{L}$ 범위에 해당하 도록 하였으며 ${ }^{14)}$, 다만 실제로 채수된 고도처리 유입수의 농도가 매우 낮아 농도 조절이 필요할 때는 2차침전지 전단 계인 생물학적 처리공정에서 유출되는 슬러지를 소량 주입 하여 그 농도를 조절하였다. 원수는 다량 채수한 다음 냉동 보관하면서 교반 후 실험을 진행함으로써 동일한 조건을 유 지하였다. 전체 실험의 원수 성상은 Table1과 같다. 응집제 는 Poly aluminium chloride (PAC) $\left(\mathrm{Al}_{2} \mathrm{O}_{3} \quad 10 \%\right.$, basicity $40 \%$ )를 사용하였다.

\section{3. 분석기기 및 방법}

채수된 시료는 $\mathrm{pH}$, 수온, 총인(T-P), 용존성인( $\left.\mathrm{PO}_{4}{ }^{3-}-\mathrm{P}\right)$ 및 탁도를 분석하였다. 측정에 사용한 시약 및 기기로써, $\mathrm{pH}$ 및 수온에는 HI2210 pH Meter (HANNA instrument, 한국)를 사용하였고, T-P 및 $\mathrm{PO}_{4}^{3-}-\mathrm{P}$ 는 DR3900 Spectrophotometer $(\mathrm{HACH}$, 미국)로 분석하였으며, 탁도는 TL2300 $(\mathrm{HACH}$, 미 국)을 사용하였다.

\section{4. 최적처리조건의 개념}

Jar-test 기반 침전부상공정 모의실험의 수질분석 결과를 검토하기 위해 '최적처리조건(Optimal treatment condition)' 의 개념을 도입하였다. 최적처리조건은 방류수 수질기준 항 목 중 1) T-P $0.2 \mathrm{mg} / \mathrm{L}$ 및 SS $10 \mathrm{mg} / \mathrm{L}$ 의 방류수질을 만족하 되, 2) 응집제를 최소로 주입한 조건에 해당하는 것으로 정
Table 1. Raw water qualities of lab-scale tests.

\begin{tabular}{cc} 
Items & Range (average) \\
\hline $\mathrm{T}-\mathrm{P}(\mathrm{mg} / \mathrm{L})$ & $0.3-3.0(1.49)$ \\
\hline $\mathrm{PO}_{4}{ }^{3-}-\mathrm{P}(\mathrm{mg} / \mathrm{L})$ & $0.03-0.66(0.164)$ \\
\hline Turbidity $(\mathrm{NTU})$ & $2.1-37.8(13.28)$ \\
\hline $\mathrm{pH}$ & $6.9-7.3(7.10)$ \\
\hline Water temperature $\left({ }^{\circ} \mathrm{C}\right)$ & $15-25(21.0)$ \\
\hline
\end{tabular}

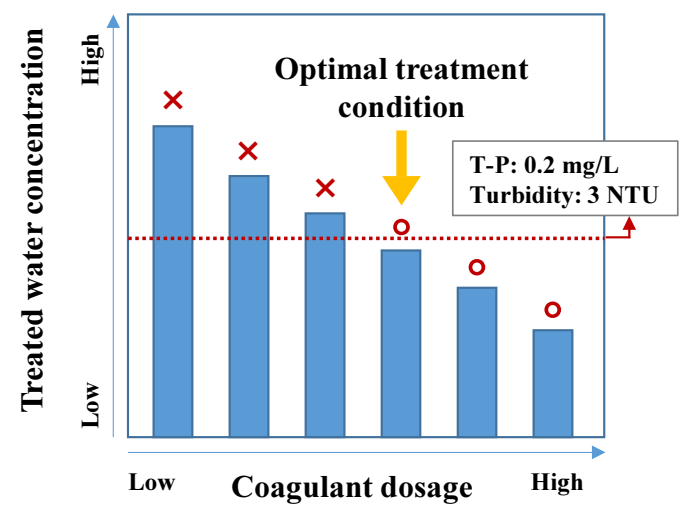

Fig.3. Concept of optimal treatment condition.

의하였다(Fig. 3). 처리수질이 낮아질수록 응집제 주입량과 슬러지 발생량이 모두 증가하므로, 실제 현장에서 운전할 때는 제거효율의 최대화를 목적으로 하지 않고 목표수질에 맞추어 운전하는 것이 일반적이다. 추가로, 실시간 분석이 어려운 수질항목인 $\mathrm{SS}$ 는 상관성이 높고, 실시간 분석과 현 장측정이 용이한 탁도로 대체하였다. 두 항목의 상관관계를 분석하여 SS $10 \mathrm{mg} / \mathrm{L}$ 은 탁도 $3 \mathrm{NTU}$ 에 대응하는 상관식에 따라 대체하였다. ${ }^{13)}$

\section{5. $\mathrm{Al} / \mathrm{P}$ 비, $\mathrm{Al} / \mathrm{PO}_{4}{ }^{3-}-\mathrm{P}$ 비 및 $\mathrm{Al} / \mathrm{T}$ 비의 정의}

알루미늄 계열의 응집제를 주입하는 응집공정에 기반한 실증플랜트에서는 각 수질오염물질의 농도에 대한 응집제 농도비를 고찰할 필요가 있다. 전체 T-P (total P)는 원수의 T-P를, 잔류 T-P (residual P)는 처리수의 T-P를 나타내며, 제 거된 인 농도(removed $\mathrm{P}$, 이하 $\Delta \mathrm{P}$ )는 원수 $\mathrm{T}-\mathrm{P}$ 에서 처리수 $\mathrm{T}-\mathrm{P}$ 를 제외한 값으로 정의된다. 마찬가지로, 제거된 탁도 (removed turbidity, 이하 $\Delta \mathrm{T}$ )는 원수 탁도(total turbidity)에 서 처리수 탁도(residual turbidity)를 제외한 값으로 정의할 수 있다(Fig.4).

본 연구에서는 T-P에 대하여 $\mathrm{Al} / \mathrm{P}(\mathrm{mol} / \mathrm{mol}), \mathrm{Al} / \triangle \mathrm{P}$ $(\mathrm{mol} / \mathrm{mol}), \mathrm{PO}_{4}{ }^{3-}-\mathrm{P}$ 에 대하여 $\mathrm{Al} / \mathrm{PO}_{4}{ }^{3-}-\mathrm{P}(\mathrm{mol} / \mathrm{mol})$ 및 $\mathrm{Al} / \Delta$ $\mathrm{PO}_{4}{ }^{3-}-\mathrm{P}(\mathrm{mol} / \mathrm{mol})$ 를 분석하였고, T-P와 $\mathrm{PO}_{4}{ }^{3-}-\mathrm{P}$ 인자간의 비 교·분석을 실시하였다. 탁도에 대하여 $\mathrm{Al} / \mathrm{T}\left(\mathrm{mg} \cdot \mathrm{L}^{-1} / \mathrm{NTU}\right)$ 및 $\mathrm{Al} / \triangle \mathrm{T}\left(\mathrm{mg} \cdot \mathrm{L}^{-1} / \mathrm{NTU}\right)$ 에 대한 분석을 수행하고 그 값을 제시하였다. 
Total P

Total turbidity

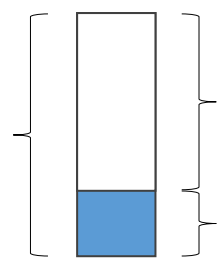

Removed $\mathrm{P}(\Delta \mathrm{P})$

Removed turbidity $(\Delta \mathrm{T})$

Residual P

Residual turbidity

Fig. 4. Definition of total, removed, and residual pollutant concentrations for $\mathrm{Al} / \mathrm{P}, \mathrm{Al} / \mathrm{PO}_{4}{ }^{3-}-\mathrm{P}$ and $\mathrm{Al} / \mathrm{T}$ ratio analyses.

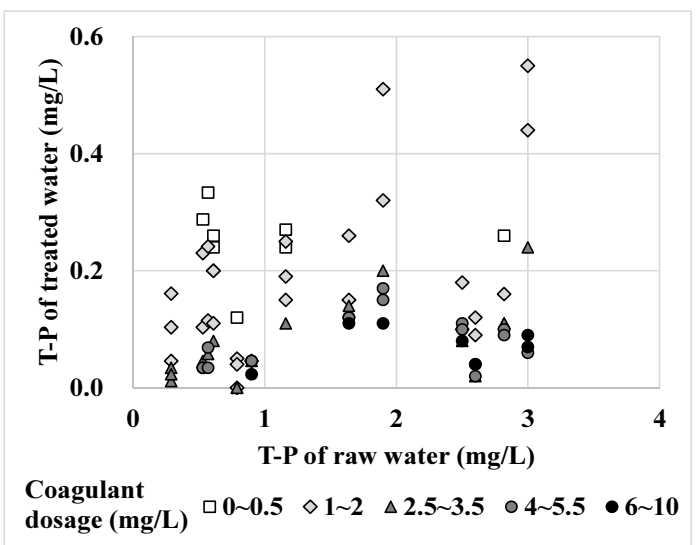

(a)

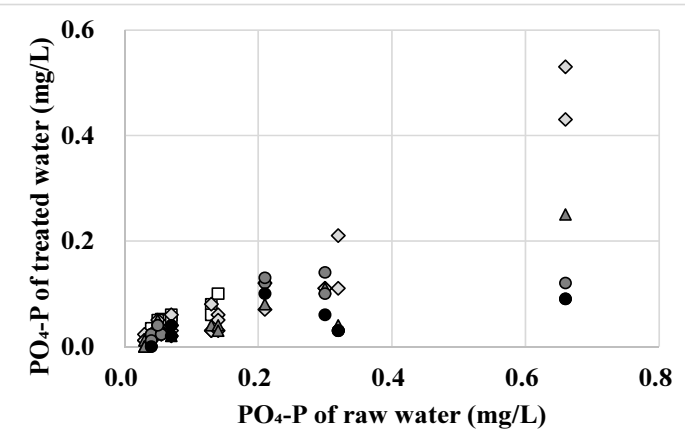

$\begin{array}{lllllll}\text { Coagulant } & \square 0 \sim 1 & \diamond 1 \sim 2 & \Delta 2 \sim 4 & \circ 4 \sim 6 & \bullet \text { more than } 6\end{array}$

(b)

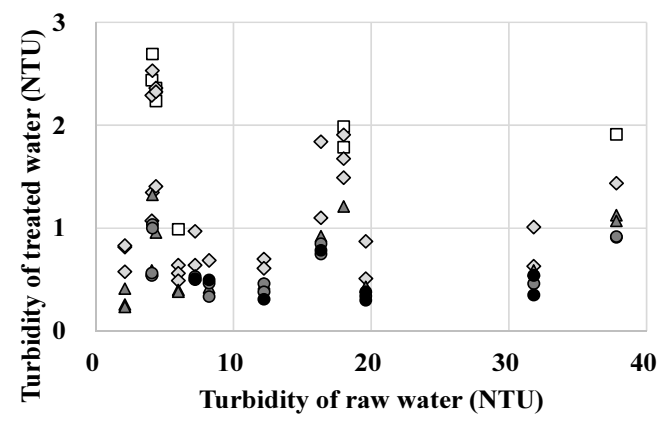

Coagulant

dosage $(\mathrm{mg} / \mathrm{L}) \quad \square 0 \sim 1 \quad \diamond 1 \sim 2 \quad \Delta 2 \sim 4 \quad \circ \sim 6 \quad$ more than 6

(c)

Fig. 5. Raw water and treated water quality according to coagulant dosage: (a) T-P, (b) $\mathrm{PO}_{4}{ }^{3-}-\mathrm{P}\left(\mathrm{PO}_{4}-\mathrm{P}\right)$, and (c) turbidity.

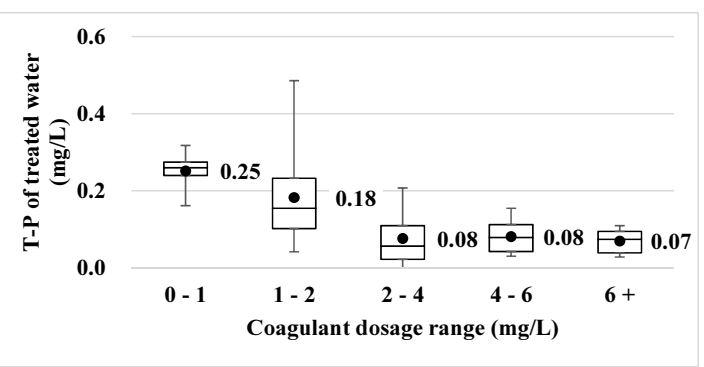

(a)

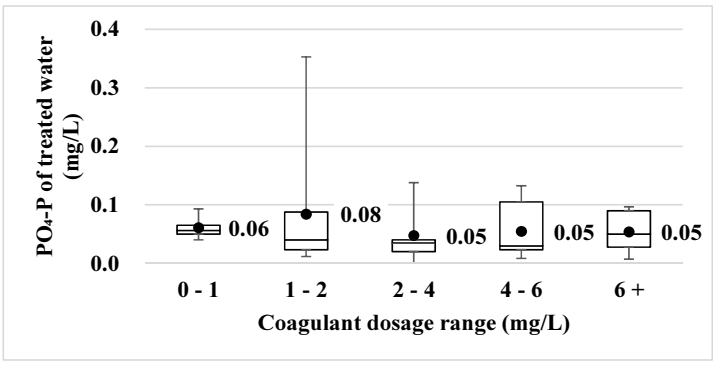

(b)

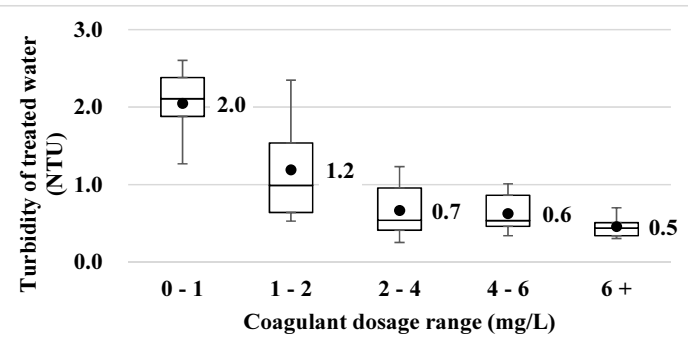

(c)

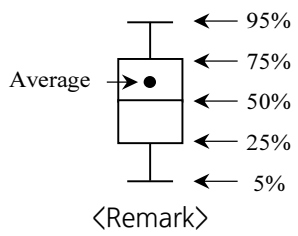

Fig. 6. Box plot of treated water quality according to coagulant dosage: (a) T-P, (b) $\mathrm{PO}_{4}{ }^{3-}-\mathrm{P}\left(\mathrm{PO}_{4}-\mathrm{P}\right)$, and (c) turbidity.

\section{3. 결과 및 고찰}

\section{1. 응집제 주입농도에 따른 원수 및 처리수질의 상관관계}

수행한 13 set Jar-test의 전체 결과 $(\mathrm{n}=77)$ 에 대하여, 응집 제 주입농도에 따른 원수 및 처리수의 $\mathrm{T}-\mathrm{P}, \mathrm{PO}_{4}{ }^{3-}-\mathrm{P}$ 및 탁도 의 관계를 나타낸 그래프와(Fig.5) 응집제 주입농도에 따른 $\mathrm{T}-\mathrm{P}, \mathrm{PO}_{4}{ }^{3-}-\mathrm{P}$ 및 탁도의 처리수질을 상자 수염 그림(Box and whisker plot) 형태로 도시하였다(Fig.6). 응집제 주입농도는 0 - 1, 1 - 2, 2-4, 4 - 6 및 6 이상 $\mathrm{mg} / \mathrm{L}$ as $\mathrm{Al}_{2} \mathrm{O}_{3}$ 의 다섯 구간으로 구분하여 제시하였다. T-P와 탁도의 경우, 전체 원 수의 유입농도 구간에 걸쳐 응집제 주입농도가 증가할수록 처리수질이 개선되는 추세인 것으로 관찰되었다(Fig.5). 응 집제 주입구간별 처리수질의 백분위수를 관찰한 결과에서 
도 T-P와 탁도에 있어 응집제 주입농도가 증가할수록 처리 수질이 개선되는 것을 확인하였다(Fig. 6). 한편, $\mathrm{PO}_{4}{ }^{3-}-\mathrm{P}$ 의 경우에는 원수의 유입농도와 응집제 주입농도 및 처리수질 사이에 뚜렷한 상관성이 관찰되지 않았다(Fig. 5, Fig.6).

\section{2. $\mathrm{Al} / \mathrm{P}$ 비, $\mathrm{Al} / \mathrm{PO}_{4}{ }^{3}-\mathrm{P}$ 비 및 $\mathrm{Al} / \mathrm{T}$ 비 분석을 통한 처리효율 검토}

전체 실험구간(원수 $\mathrm{T}-\mathrm{P} 0.3-3.0 \mathrm{mg} / \mathrm{L}$ )에 대한 $\mathrm{Al} / \mathrm{P}$ 비 및 $\mathrm{Al} / \triangle \mathrm{P}$ 비의 분석결과를 Fig. 7에 제시하였다. Fig. 7(a)는 y 축의 범위를 $0-4 \mathrm{mg} / \mathrm{L}$ 로 하여 원수의 전체구간을 나타내 었으며, Fig.7(b)에서는 최적처리조건 기준농도인 $0.2 \mathrm{mg} / \mathrm{L}$ 구간에서의 특징을 더 상세하게 살펴보기 위하여 0.0 - 0.6 $\mathrm{mg} / \mathrm{L}$ 구간을 확대하여 제시하였다.

여기에서는 앞서 제시한 '2.4. 최적처리조건의 개념'을 적 용하여 $\mathrm{Al} / \mathrm{P}$ 비, $\mathrm{Al} / \mathrm{PO}_{4}{ }^{3-}-\mathrm{P}$ 비 및 $\mathrm{Al} / \mathrm{T}$ 의 범위를 도출하였다. 즉, Jar-test 기반의 모의실험에 있어 최적처리조건의 정의인 T-P $0.2 \mathrm{mg} / \mathrm{L}$ 및 탁도 $3 \mathrm{NTU}$ 를 만족하는 최저 응집제 주입 조건을 활용하여 $\mathrm{Al} / \mathrm{P}$ 비, $\mathrm{Al} / \mathrm{PO}_{4}{ }^{3-}-\mathrm{P}$ 비 및 $\mathrm{Al} / \mathrm{T}$ 의 범위를 검 토하였다.

그 결과, $\mathrm{Al} / \mathrm{P}$ 비 및 $\mathrm{Al} / \triangle \mathrm{P}$ 비의 값은 원수 농도에 따라 달 라지는 경향을 보였으며, 이는 기존 문헌에서의 내용과도 부합한다. ${ }^{7,11,12)}$ 원수 T-P $0.29-0.57 \mathrm{mg} / \mathrm{L}$ 일 경우(편의상, 이 하 저농도) $\mathrm{Al} / \mathrm{P}$ 비는 1.05 - 1.15 로 평균 1.09 에 해당하는 것 으로 분석되었으며, $0.61-3.00 \mathrm{mg} / \mathrm{L}$ 의 범위를 갖는 경우 (편의상, 이하 고농도) 0.12 - 0.67로 평균 0.37 의 값을 갖는 것으로 나타났다. 이는 USEPA (1976) 등에서 제시한 $\mathrm{Al} / \mathrm{P}$ 비 범위인 1.9 - 3.7, Ministry of Environment (2012)에서 제 시한 1.0 - 7.2의 값보다 현저하게 낮은 수치임을 확인하였 다. ${ }^{7,11,12)}$ 원수의 농도 범위에 따라 차이가 발생하는 것으로 분석되었는데 원수의 농도가 높아질수록 $\mathrm{Al} / \mathrm{P}$ 비는 감소하 였다. $\mathrm{Al} / \triangle \mathrm{P}$ 비의 분석 결과, 저농도에서 1.34 - 1.63(평균 1.46), 고농도에서 $0.12-0.74$ (평균 0.42)로 나타났으며, 이 때의 제거효율은 $89 \%$ 이상으로 분석되었다. 이는 단위 농 도의 T-P를 제거하는데 있어, 저농도의 T-P를 처리하기 위 해서는 고농도일 때에 비해 더 높은 농도 비율로 알루미늄 계열의 응집제를 주입해야 함을 의미한다. $\mathrm{Al} / \mathrm{P}$ 비와 $\mathrm{Al} / \Delta \mathrm{P}$ 비를 비교하면, $\mathrm{Al} / \triangle \mathrm{P}$ 비가 $\mathrm{Al} / \mathrm{P}$ 비에 비해 더 큰 값을 나타 내었다. $\mathrm{Al} / \mathrm{P}$ 는 응집제 주입농도와 원수의 유입농도에 의해 결정되는 데 비해, $\mathrm{Al} / \triangle \mathrm{P}$ 비는 추가로 처리수질도 고려한다 는 차이가 있는 점에 유의가 필요하다.

$\mathrm{PO}_{4}{ }^{3-}-\mathrm{P}$ 를 대상으로 동일한 분석을 수행하였다. $\mathrm{PO}_{4}{ }^{3-}-\mathrm{P}$ 의 경우 방류수 수질기준 항목은 아니지만 T-P와 비교하였을 때 측정의 편의성을 가지므로 실제 하수처리장에서 광범위 하게 적용되고 있다. 인(P)을 제거하는 알루미늄(Al)의 몰비 라는 개념은 동일하나 T-P인자와의 비교를 위하여 편의상 $\mathrm{Al} / \mathrm{PO}_{4}{ }^{3-}-\mathrm{P}$ 비 및 $\mathrm{Al} / \triangle \mathrm{PO}_{4}{ }^{3-}-\mathrm{P}$ 비로 표기하였다(Fig. 8). Fig. 8(a)에서는 $\mathrm{PO}_{4}{ }^{3-}-\mathrm{P}$ 의 원수 범위 $0-0.7 \mathrm{mg} / \mathrm{L}$ 의 전 구간에 대하여 제시하였으며, Fig.8(b)에서는 $0-0.3 \mathrm{mg} / \mathrm{L}$ 까지의 범위에 대하여 더 상세하게 제시하였다. T-P의 경우에는 최 적처리조건 기준농도를 하수처리시설 방류수 수질기준을 바탕으로 하여 $0.2 \mathrm{mg} / \mathrm{L}$ 로 설정하였으나, $\mathrm{PO}_{4}{ }^{3-}-\mathrm{P}$ 의 경우에 는 방류수 수질기준 내에 해당 항목이 존재하지 않는다. $\mathrm{T}-\mathrm{P}$ 와 $\mathrm{PO}_{4}{ }^{3-}-\mathrm{P}$ 의 처리수질 측정값의 상관관계를 분석하였 을 때, $\mathrm{y}=0.5 \times\left(\mathrm{R}^{2}=0.5\right)$ 의 상관성을 갖는 것을 확인하였 다 $\left(\mathrm{y}=\mathrm{PO}_{4}{ }^{3-}-\mathrm{P}, \mathrm{x}=\mathrm{T}-\mathrm{P}\right)$. 따라서, $\mathrm{PO}_{4}{ }^{3-}-\mathrm{P}$ 의 최적처리조건 기준농도를 $0.1 \mathrm{mg} / \mathrm{L}$ 로 설정하였다. 미처리 상태인 원수의 $\mathrm{PO}_{4}{ }^{3-}-\mathrm{P}$ 유입농도가 이미 $0.1 \mathrm{mg} / \mathrm{L}$ 이하인 조건에서는 각 set별 최저 응집제 주입농도를 최적처리조건으로 선정하였 다. 도출된 $\mathrm{Al} / \mathrm{PO}_{4}{ }^{3-}-\mathrm{P}$ 비는 1.1 - 15.2의 넓은 범위를 나타내 었으며(평균 6.68), $\mathrm{Al} / \triangle \mathrm{PO}_{4}{ }^{3-}-\mathrm{P}$ 비 또한 7.6 - 30.4(평균 15.9) 로 광범위한 값을 갖는 것으로 분석되었다. $\mathrm{PO}_{4}{ }^{3-}-\mathrm{P} \quad 0.1$ $\mathrm{mg} / \mathrm{L}$ 이상의 조건에서 $\mathrm{Al} / \mathrm{PO}_{4}{ }^{3-}-\mathrm{P}$ 비는 0.6 - 4.1의 범위이며 평균값은 2.49 로 도출되어, 기존문헌에서 조사된 $\mathrm{Al} / \mathrm{P}$ 비와 유사한 값을 갖는 것으로 분석되었다. 이와 같은 $\mathrm{Al} / \mathrm{PO}_{4}{ }^{3-}-\mathrm{P}$ 비가 갖는 큰 변동성으로 인해, 현장운전 시 낮은 용존성 인 농도를 갖는 원수가 유입될 경우에는 $\mathrm{Al} / \mathrm{PO}_{4}{ }^{3-}-\mathrm{P}$ 비의 적용 에 한계가 있으며, 원수 농도가 그 이상일 경우에도 $\mathrm{Al} / \mathrm{P}$ 비 에 비해 안정성이 떨어지고 부정확도가 높을 것으로 판단되 었다. $\mathrm{Al} / \mathrm{PO}_{4}{ }^{3-}-\mathrm{P}$ 비 및 $\mathrm{Al} / \Delta \mathrm{PO}_{4}{ }^{3-}-\mathrm{P}$ 비를 비교하면, $\mathrm{Al} / \Delta$ $\mathrm{PO}_{4}{ }^{3-}-\mathrm{P}$ 비가 $\mathrm{Al} / \mathrm{PO}_{4}{ }^{3-}-\mathrm{P}$ 비에 비해 더 큰 값을 나타내었다.

탁도에 대한 $\mathrm{Al} / \mathrm{T}$ 비, $\mathrm{Al} / \triangle \mathrm{T}$ 비의 분석결과를 Fig.9에 제 시하였다. 탁도 또한 0 - $40 \mathrm{NTU}$ 의 전체범위(Fig.9(a))와 0 - 3 NTU의 구간범위(Fig. 9(b))로 구분하여 제시하였다. 처리수의 탁도는 전 구간에 걸쳐 $3 \mathrm{NTU}$ 이하로 분석되어 저농도의 응집제 주입만으로도 탁도를 잘 제거할 수 있는 것으로 나타났다. 원수의 구간에 따라 저농도(5 NTU 이하) 및 고농도(5 NTU 이상)로 나누었으며, $\mathrm{Al} / \mathrm{T}$ 비는 저농도에 서 0.12 - 0.32(평균 0.17), 고농도에서 0.01 - 0.06(평균 0.03) 으로 분석되었다. $\mathrm{Al} / \Delta \mathrm{T}$ 비는 저농도에서 0.20 - 0.42(평균 0.22 ), 고농도에서 $0.01-0.07$ (평균 0.04 )로 분석되었다. $\mathrm{Al} / \mathrm{T}$ 비 및 $\mathrm{Al} / \triangle \mathrm{T}$ 비 또한 원수 농도가 낮을 때가 높을 때에 비 해 수치가 증가하는 것이 확인되었다. 이는 단위 농도의 탁 도를 제거하는데 있어 저농도의 탁도를 처리하기 위해서는 고농도의 탁도에 비해 더 높은 농도 비율로 알루미늄계열 의 응집제를 주입해야 함을 의미한다. $\mathrm{Al} / \mathrm{T}$ 비 및 $\mathrm{Al} / \triangle \mathrm{T}$ 비 를 비교하면, $\mathrm{Al} / \triangle \mathrm{T}$ 비가 $\mathrm{Al} / \mathrm{T}$ 비에 비해 더 큰 값을 나타내 었다.

$\mathrm{Al} / \mathrm{P}$ 비, $\mathrm{Al} / \mathrm{PO}_{4}{ }^{3-}-\mathrm{P}$ 비 및 $\mathrm{Al} / \mathrm{T}$ 비에 대하여 종합적으로 비 교·검토하였을 때 최적조건 비의 크기는 $\mathrm{Al} / \mathrm{PO}_{4}{ }^{3-}-\mathrm{P}$ 비 > $\mathrm{Al} / \mathrm{P}$ 비 $>\mathrm{Al} / \mathrm{T}$ 비의 순으로 분석되었으며, 최적조건 비가 분포 하는 범위(range)의 안정성은 $\mathrm{Al} / \mathrm{P}$ 비 $>\mathrm{Al} / \mathrm{T}$ 비 $>\mathrm{Al} / \mathrm{PO}_{4}{ }^{3-}-\mathrm{P}$ 비의 순서로 나타났다. 이상의 결과로부터, $\mathrm{SeDAF}$ 공정에 


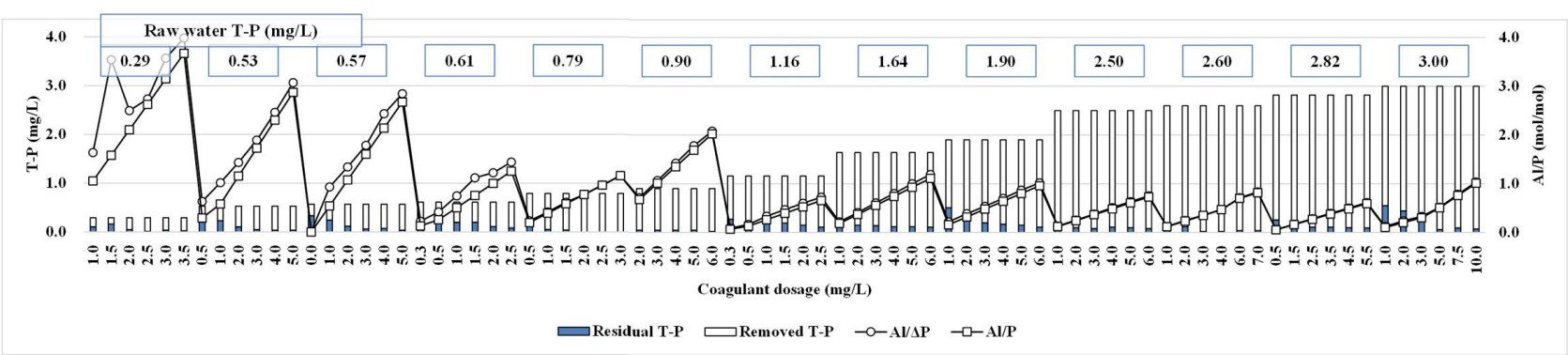

(a)

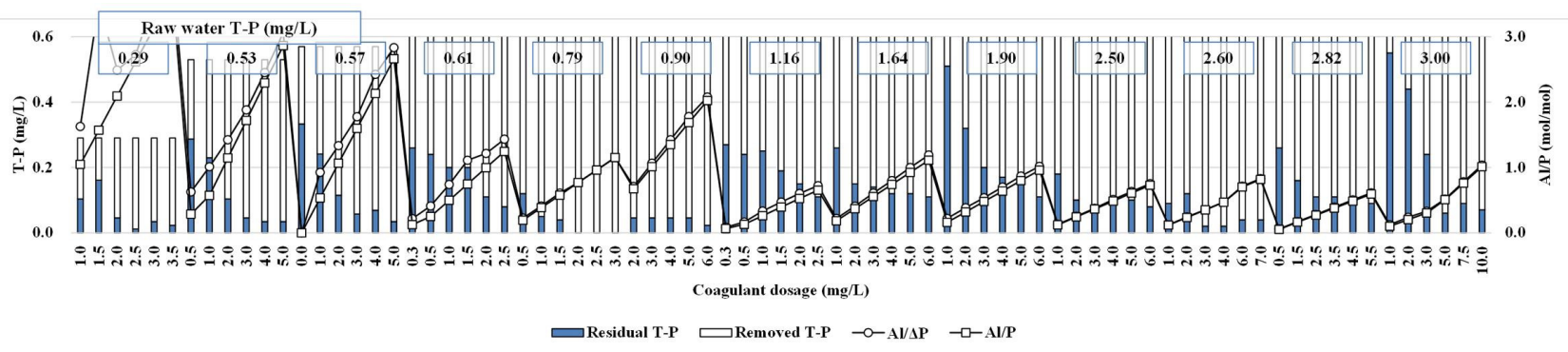

(b)

Fig. 7. Al/P ratio in the range of (a) $0.0-4.0 \mathrm{mg} / \mathrm{L}$ and (b) $0.0-0.6 \mathrm{mg} / \mathrm{L}$ of $\mathrm{T}-\mathrm{P}$ in treated water.

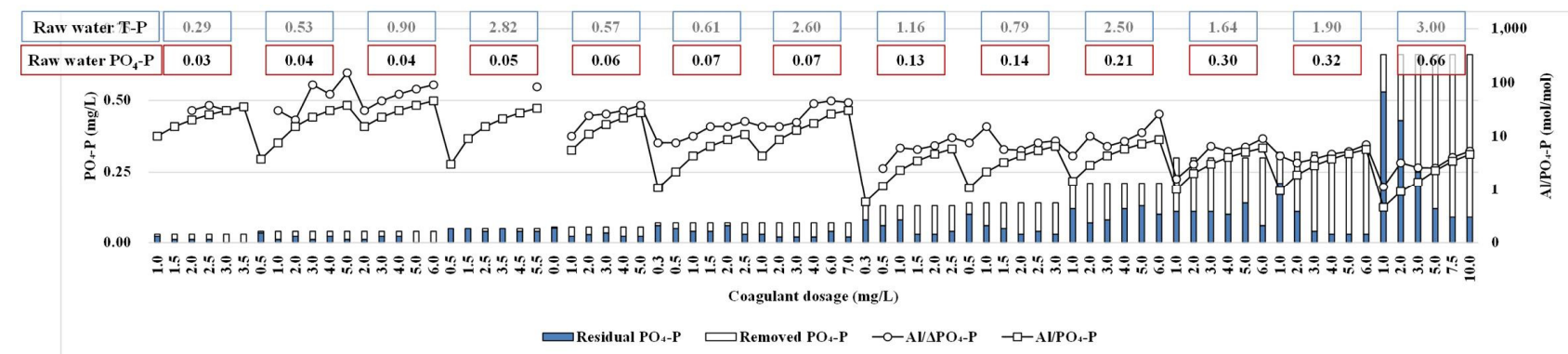

(a)

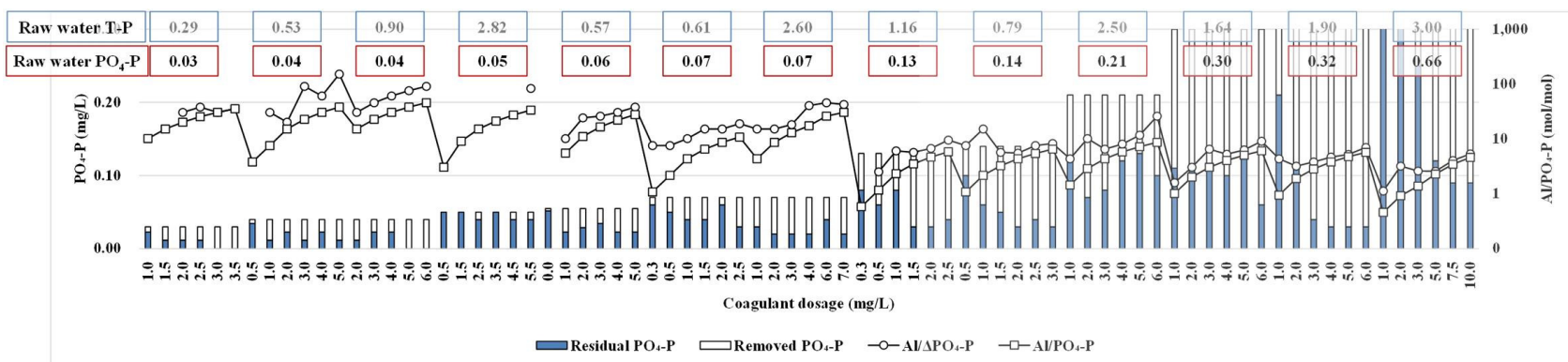

(b)

Fig. 8. $\mathrm{Al} / \mathrm{PO}_{4}{ }^{3-}-\mathrm{P}$ ratio in the range of (a) $0.0-0.7 \mathrm{mg} / \mathrm{L}$ and (b) $0.0-0.3 \mathrm{mg} / \mathrm{L}$ of $\mathrm{PO}_{4}{ }^{3-}-\mathrm{P}$ in treated water.

서 응집제 주입조건에 대한 모니터링 인자로는 범위 안정성 이 높은 $\mathrm{Al} / \mathrm{P}$ 비를 적용하는 것이 가장 효율적일 것으로 판 단된다. 또한 해당 인자는 적절한 값의 크기를 갖고 있어 현 장활용도 측면에서도 가장 용이할 것으로 사료된다. $\mathrm{Al} / \mathrm{T}$ 비 의 경우 $\mathrm{Al} / \mathrm{P}$ 비보다 범위 안정성이 낮고 값의 크기가 매우 작아 적용에 유의할 필요가 있는 것으로 나타났다. 한편, $\mathrm{Al} / \mathrm{PO}_{4}{ }^{3-}-\mathrm{P}$ 비의 경우에는 범위 안정성이 매우 낮아 해석 시
각별한 주의가 필요하며, 가능한 한 활용하지 않는 것이 바 람직할 것으로 판단된다. 결론적으로, 현장활용성 측면에서 가장 우수한 인자는 T-P를 활용한 $\mathrm{Al} / \mathrm{P}$ 비 또는 $\mathrm{Al} / \triangle \mathrm{P}$ 비인 것으로 판단하였다. 또한 이를 통해 최적의 응집제 주입농 도를 산정함으로써, 응집제 사용량 저감 및 슬러지 발생량 감소의 효과가 있을 것으로 기대한다. 


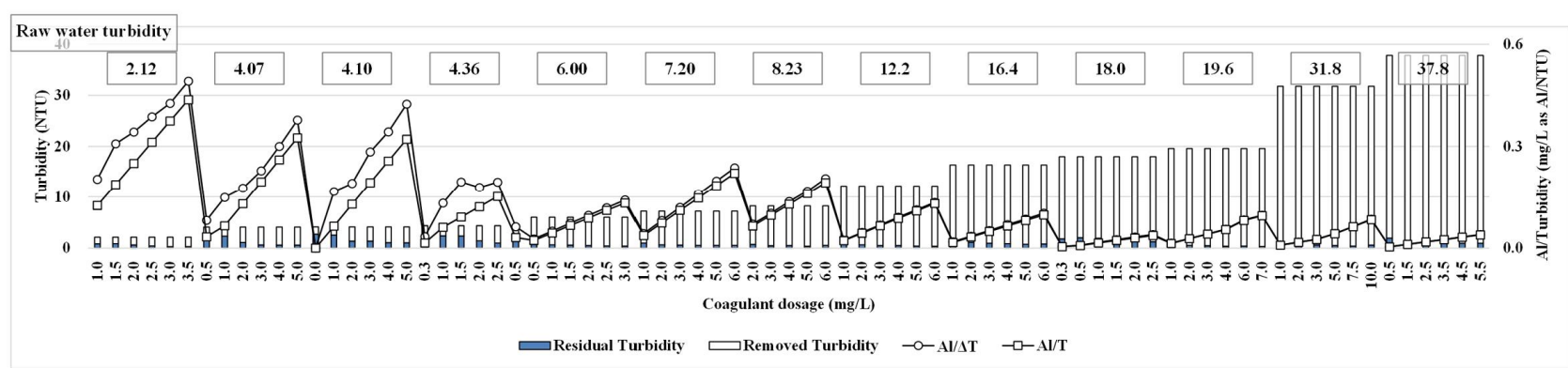

(a)

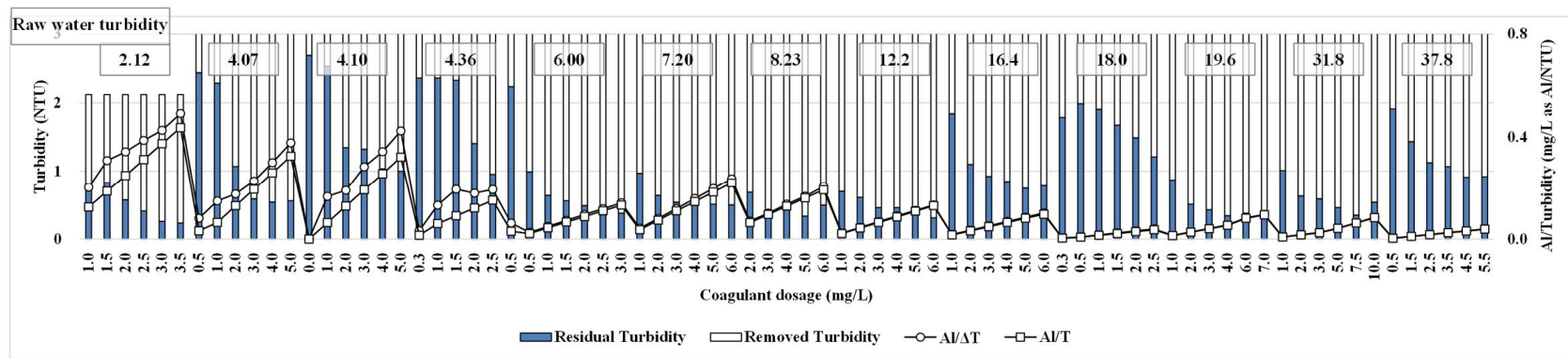

(b)

Fig. 9. Al/T ratio in the range of (a) $0-40$ NTU and (b) $0-3$ NTU of turbidity in treated water.

\section{4. 결론}

본 연구에서는 하수처리시설에서 기존의 인 고도처리공 정을 대체하기 위하여 개발된 일체형 침전부상공정(SeDAF process)의 운전인자를 결정하고 실증플랜트에서의 적용성 을 검증하기 위하여, 2차침전지 유출수를 대상으로 다양한 Lab-scale 모의실험을 수행하였다. 특히, 응집공정에서 적정 한 응집제 주입조건을 도출하기 위해 각 운전조건에 대해 $\mathrm{Al} / \mathrm{P}$ 비, $\mathrm{Al} / \mathrm{PO}_{4}{ }^{3-}-\mathrm{P}$ 비 및 $\mathrm{Al} / \mathrm{T}$ (Al/Turbidity)비를 분석하고 비교·검토하였다. 본 연구의 주요한 결론은 다음과 같다.

1) Jar-test 기반 모의실험을 수행하여 응집제 주입농도에 따른 원수 및 처리수질의 상관관계를 검토한 결과, T-P와 탁도는 응집제 주입농도의 증가에 따라 처리수질이 개선되 는 뚜렷한 상관관계가 있음을 확인하였다. $\mathrm{PO}_{4}{ }^{3-}-\mathrm{P}$ 의 경우에 는 응집제 주입농도와 처리수질 개선 정도의 사이에 유의미 한 상관성이 관찰되지 않았다.

2) $\mathrm{SeDAF}$ 공정을 대상으로 응집공정에 대한 적정 운전인 자를 도출하기 위하여 $\mathrm{Al} / \mathrm{P}$ 비를 분석한 결과, 원수 T-P 0.6 $\mathrm{mg} / \mathrm{L}$ 이하의 저농도일 경우의 $\mathrm{Al} / \mathrm{P}$ 비는 1.05 - 1.15 (평균 1.09 )의 범위의 값을 갖고, 원수 T-P $0.6-3.0 \mathrm{mg} / \mathrm{L}$ 범위의 고농도일 경우에는 0.12 - 0.74(평균 0.37)의 범위의 값을 갖 는 것으로 나타났다. $\mathrm{Al} / \mathrm{P}$ 비는 원수의 T-P 유입농도가 증가 함에 따라 감소하여 유입농도에 따라 적정 범위가 달라진다 는 사실에 유의할 필요가 있었다.

3) $\mathrm{Al} / \mathrm{PO}_{4}{ }^{3-}-\mathrm{P}$ 비를 분석한 결과, 원수의 유입농도가 낮을 경우 평균 6.7 의 큰 값을 갖고 원수의 수질에 따라 매우 큰 폭으로 변동하는 것으로 나타나, 인 고도처리공정의 운전인
자로서 적당하지 않은 것으로 판단되었다.

4) $\mathrm{Al} / \mathrm{T}$ 비를 검토한 결과, 원수 $5 \mathrm{NTU}$ 이하의 저농도일 경우에 $\mathrm{Al} / \mathrm{T}$ 비는 0.12 - 0.32(평균 0.17), $5 \mathrm{NTU}$ 이상의 고 농도일 경우에 $0.01-0.06$ (평균 0.03)의 낮은 값을 갖는 것 으로 나타났다. 탁도의 경우 전체의 Jar-test 결과에서 최종 처리수질이 모두 안정적으로 $3 \mathrm{NTU}$ 이하를 달성하여, T-P 및 $\mathrm{PO}_{4}{ }^{3-}-\mathrm{P}$ 에 비해 더 용이하게 처리가능한 것으로 나타났 다. 따라서, $\mathrm{Al} / \mathrm{T}$ 비는 $\mathrm{SeDAF}$ 공정에서 응집제 주입조건에 대한 모니터링 항목으로서의 적합성이 상대적으로 낮은 것 으로 판단되었다.

5) 하수처리공정에서 인 고도처리를 위해 개발된 SeDAF 공정의 응집조건을 모니터링하기 위한 인자로서 $\mathrm{Al} / \mathrm{P}$ 비, $\mathrm{Al} / \mathrm{PO}_{4}{ }^{3-}-\mathrm{P}$ 비 및 $\mathrm{Al} / \mathrm{T}$ 비를 비교·검토한 결과, $\mathrm{T}-\mathrm{P}$ 를 활용한 $\mathrm{Al} / \mathrm{P}$ 비 또는 $\mathrm{Al} / \triangle \mathrm{P}$ 비가 안정성 및 현장활용성 측면에서 가 장 적절한 것으로 판단되었다.

6) $\mathrm{SeDAF}$ 공정의 $\mathrm{Al} / \mathrm{P}$ 비는 기존 문헌들이 보고하고 있는 $\mathrm{Al} / \mathrm{P}$ 비 값인 1.0 - 7.2보다 뚜렷하게 낮은 결과를 보였다. 따 라서, $\mathrm{SeDAF}$ 공정의 도입을 통해 응집제 주입농도의 저감 뿐만 아니라 슬러지 발생량 또한 감소시킬 수 있을 것으로 기대된다.

\section{Acknowledgement}

본 연구는 한국건설기술연구원 주요사업의 연구비 지원 으로 수행되었습니다(과제번호: 20200039-001). 이에 감사 드립니다. 


\section{References}

1. R. G. Wetzel, Limnology, 3rd ed., Academic Press, Massachusetts, USA, pp. 239-288(2001).

2. B. C. Kim, S. H. Sa, M. S, Kim, Y. K. Lee, J. K. Kim, The limiting nutrient of eutrophication in reservoirs of Korea and the suggestion of a reinforced phosphorus standard for sewege treatment effluent, J. Korean Soc. Water Environ., 23(4), 512-517(2007).

3. J. K. Kim, S. H. Lee, H. H. Bang, S. O. Hwang, Characteristics of algae occurrence in lake Paldang, J. Korean Soc. Environ. Eng., 31(5), 325-331(2009).

4. H. K. Park, Survey method relating freshwater phytoplantkon for the management of water resources, J. Korean Soc. Environ. Eng., 29(6), 593-609(2007).

5. H. H. Lee, A case study on the evaluation of efficiency treatment plant TP treatment facility in public sewage source, Master thesis, Chonnam National University(2014).

6. H. Y. Chang, Phosphorus removal by hydroxyapatite crystallization using limestone filter bed in wastewater effluent, Master thesis, University of science and technology (2017).

7. Ministry of Environment, A Study on Improvement Methods for Treatment Efficiency of Phosphorus Treatment Facilities, Ministry of Environment, Sejong, Korea, pp. 1-183(2012).

8. Korea Water and Wastewater Works Association, Sewer Facility Standards, Ministry of Environment, Sejong, Korea, pp. 1-1173(2011).

9. Korea Ministry of Government Legislation, Sewege System Statistic Data of 2018, http://me.go.kr, March(2020).

10. D. J. Tian, B. Lee, Y. J. Lee, H. B. Jun, Effect of magnesium and calcium ions on the phosphorus removal by aluminium coagulation, J. Korean Soc. Environ. Eng., 33(4), 231-236(2011).

11. University of Texas Medical Branch, Phosphorus removal and disposal from municipal wastewater, University of Texas Medical Branch, Texas, USA(1971).

12. United States Environmental Protection Agency (USEPA), Process Design Manual for Phosphorus Removal, United States Environmental Protection Agency, Washington D.C., USA(1976).

13. Y. J. Jang, J. H. Jung, H. Y. Chang, N. R. Park, H. M. Lim, W. J. Kim, Decision of optimal coagulant dosage for SeDAF (sedimentation and dissolved air flotation) process applicable to enhanced phosphorus removal, KSWST Jour. Wat. Treat., 28(4), 33-42(2020).

14. S. J. Kim, S. M. Park, H. Y. Park, K. C. Lee, O. S. Kwon, Best Available Technology and Management Practice using Physicochemical Methods for Phosphorus Removal in Municipal Wastewater Treatment Plants in the Priority Areas of 4 Major Rivers, National Institute of Environmental Research, Incheon, Korea, pp. 1-23(2010).

\section{Authors}

\section{Yeoju Jang}

University of Science and Technology (UST, KICT School), Civil \& Environmental Engineering, Master of Engineering, ORCID(잉 0000-0001-5858-5548

\section{Jinhong Jung}

Korea Institute of Civil Engineering and Building Technology (KICT), Department of Land, Water and Environment Research, Environmental Resource Research Center, Ph.D., ORCID(1) 0000-0002-9698-597X

\section{Kwangho Ahn}

Korea Institute of Civil Engineering and Building Technology (KICT), Department of Land, Water and Environment Research, Environmental Resource Research Center, Ph.D., ORCID(D) 0000-0002-1605-0577

\section{Hyunman Lim}

Korea Institute of Civil Engineering and Building Technology (KICT), Department of Land, Water and Environment Research, Environmental Resource Research Center, Senior Researcher, ORCID(1) 0000-0001-5821-4173

\section{Weonjae Kim}

Korea Institute of Civil Engineering and Building Technology (KICT), Department of Land, Water and Environment Research, Environmental Resource Research Center, Ph.D. \& Professor, ORCID(1) 0000-0001-5676-5131 